Journal of Social and Development Sciences

Vol. 4, No. 10, pp. 467-477, Oct 2013 (ISSN 2221-1152)

\title{
New Sight to Economic Development Progress in Developing Countries
}

\author{
*Maryam Jafari Galooyek, Zaleha Mohd Noor \\ University Putra Malaysia, Malaysia \\ *galuoyek79@yahoo.com
}

\begin{abstract}
Economic development is a current phrase that seems so easy to define, but in truth is too equivocal word. Although this word was born after the Second World War, Smith's invisible hand has already pointed the notion of economic development as growth in income per capita. Even today, economic development is synonym with the high level of income per capita and reduction of poverty to achieve the improved well-being and standard of living. It is the rational result of deep gap among poor and rich countries. Hence, development is not a word which we can put border for each especial dimensions. Development must include the other dimensions like social, economic, cultural and political development, all moving together. In this paper, we will show the usage of economic growth to explain a special filed of development is a mistake. A society will experience economic development when the whole of the dimensions of development is achieved along with economic growth. The final goal of this paper is to show a new viewpoint of development progress to prepare the background for human talent to flourish.
\end{abstract}

Keyword: Economic Development, Economic Growth, Human life, Well-being, Poverty

\section{Introduction}

Development is an abstruse key concept, which everyone knows it but its exact definition is too difficult to explain. Development includes various notion of society; politics, economics, and culture, as result different groups of scholars try to define it according to their specialized area. In addition, several level of income, technology, education, and health or totally the public welfare have caused that the countries divide to three groups of countries, which named developed, developing and under developing countries. In other word, development is a reason to movement and transfer of communities to increase the level of welfare of people. The use of word of development deployed after the World War II, for example, Nielsen believes by ending the Second World War, decolonization and independent of countries as new economies, they understood that they should exit from poverty, misery and destitution and depart to situation of countries which are pioneer of the level of income and well-being (Nielsen, 2011). Nevertheless, most experts of development consider the longer history for the word of development. Grabowski and his colleagues, with relying on theory of Clark (1940), show the economic development was born after the Great Depression, it means in1929, that it more explains the conditions of residents of non-advanced capitalism countries (Grabowski, Self, \& Shields, 2007). If the word of development is synonym by concepts like increasing in income and improving level of standard of living, we can say that Smith (1776) has also pointed development, since he presumes that economic growth will cause disappearing the poverty and bettering the income of inhabitances of society.(Smith, 2006) Moreover, Sen (2001) displays that the economic view to development is a motive to say that the time of born of notion of development is 1676 when Sir William Petty focuses on the subsistence and level of income of habitants, also he describes in each community, people should have security and happiness.

The most important point, which we should talk about it, is in the mind of people of different countries including rich or poor, the word of development is reminding economic development. In other word, development means the raise in national production and income, availability of advanced technology, decrease of mortality, and improvement of level of education and health. Then Smith (1776), RosensteinRodan (1957), Singer (1952), Lewis (1955), Rostow (1955), Prebisch (1988), Todaro (1989), Helpman (2004), and Yusuf and Deaton (2009) are theoreticians who have illustrated augmenting in national income and employment is the our major goal in each country. Of course, it is undeniable that economic development has closely relationship with concepts like growth of food resource, cloths and housing, health and education services, and changing in structure of production. Although these factors are considered as required 
operative for economic growth, economic growth is not comprehensive equivalent to economic development, as well as economic development cannot lonely be explain the meaning of development. Economic growth and development and public welfare are necessary to development process but they are not enough.

Altogether, aim of our study is to display development as integration of positive evolution of economic, social, political, and cultural aspects, which they are not single executable in society. In better word, progress of economy in each community will happen, when a society has the ideal, effective and optimum situation to attain political, cultural, and social advance. Hence, not only social development, political development, economic or cultural development are not complete concepts but also they cannot be separately considered as the final goal for each country. What, for countries, is debated, discussed, and planned, as the final goal is achievement development as complete and perfect word to have the best and idealist position for life in each community. Then, against the theories, which are related to topics of development, concentrate on developing and under developing countries, we, by new definition of development as conclusive aim, will indicate in countries, which are known as developed societies the conditions of development have not been implemented yet and in most developed countries some people are deprived from their primary human rights. In this study, development will be defined as preparing the required background to flourish human talent to gain the highest level of satisfaction and happiness in their life. For this purpose in part two, we will investigate the essential literature to offer our new definition of development. Part 3 will focus on data and needed information to show the lack of ability of economic growth and even economic development to explain the word of development. Finally, in part four we will offer a summary and result what has been said in this study.

\section{Background of definitions of economic development}

To explain the word of development, there are so many definitions, which it seems the economic approach of compliment of development is the strongest approaches in the mind of population. Moreover, the biggest imperfection of this thinking, to describe the word of development, is to investigate and assess the situation of development by progressing in the quantitative production or changing in national income as well as using the advanced technology and having the better education and health services. For this end we can strongly

say that infrastructure of this approach returns into the birth of economic in 1776 by Adam Smith. Since he clarifies the human, pursue directions, which achieve, distribute, and grow the wealth easily. In other word, the aim of the human life is accessing the highest level of satisfaction that will be available by attaining more wealth.(Smith, 2006) Although, sometimes, scholars of other subset of social sciences offer their view about the necessity of moving forward in their specialty, up to end of twentieth century, economic attitudes was the major factor to qualify the development situation. As result, each economic progress could be considered as being development oriented of each community. This thinking caused (Smith, 1776), (Malthus, 1926), (Ricardo \& Hartwell, 1971), (Marx \& Engels, 1967), and (Weber, Baehr, \& Wells, 2002) focus on economic growth as final goal of human life. We can forcefully say that the discussion of development started from eighteenth century when the Europe was experiencing the Renaissance and industrial revolution. Pressure of industrialization and growth of technology with takeover of market of Colonial countries are reasons to divide the world into two groups: first, advanced Christian and second, others. Nevertheless, the occurrence of Great Depression in the first half of twentieth century incurred Western countries could not move forward, European countries also the United States meet turndown insofar as unemployment rate fell to $25 \%$ in the United States. Great Depression in 1929 entailed the name of Keynes shins like Smith, as advocate of capitalism, and Marx, as critic of capitalism, among other economists.

Although the general theory of Keynes was as a solution to escape from turndown and government has been the key and effective factor to this goal, he like other colleges, depicts the aim of economic study is to attain high rate of economic growth to feel the well-being. In addition, Keynes believes that the intervention of government in balancing the market is necessary and undeniable (Keynes, 2006). Then we can say the new view of Keynes caused to formulate the modern development process by economists. Marshal plan was good sample from a long run planning of development, to create a formidable market for American goods to prevent second dominate of Communism in Europe (Kindleberger, 2009). After World War II, World was divided two groups: first world or west block which includes capitalism, and second world or east block that they consists communism and socialism areas. Nevertheless, there were so many countries, which did not 
belong to any groups, and they were mainly poor communities. This kind of division of the universe as well as countries had been destroyed in the war and finally the newly independent countries after Second World War were motives to appear the thinking of modern development concept although most of them follow the notion of economic growth. In other world, the main goal of policy making of economic development in the fifties was to reach economic growth. Since most economists believed, we can eliminate the imbalance in income and social unbalance by economic growth and reconstruction of structures. The theory of Big Push of Rosenstein(Rosenstein-Rodan, 1957) or the stages of growth of Rostow (Rostow, 1955) are samples of this kind of thinking. Rosenstein, in Big Push, emphasizes to remove all the impediments of economic development in developing countries; we need a comprehensive planning in total economic sectors in the same time. He shows that in all poor countries we face downturn as result only by investing in all economic sectors of a community simultaneously, we can move to better economic situation in first stage and economic development in the second stage. Moreover, poor countries because of absence of market mechanism to adjust the prices as well as the weakness of the productive factors, need powerful government to allocate the limited resources to development plans (Rosenstein-Rodan, 1957).

Singer is another development economist that offers his development theory in format of economic growth theories. He believes the economy is not a permanently truth, then we cannot expect its rules are practical in all countries. He illustrates what is cause of economic growth, in industrial countries, has been the imbalance commercial relationship between rich and poor countries. He, in his theory, has emphasized that most countries from third world usually are only exporters of high-grade row materials and low price, also they are importers the manufactured goods by high added value from industrial countries whose access high political power and technology. It is clear that the profit of trade will belong to rich societies (Singer, 1952). Myrdal is one of the most prominent economists who worked on social situation of countries. He disagrees with economic scientists who believe the social imbalances are the result of absence of economic. He displays the unbalance situation in social position is the major factor to low level of economic growth (Myrdal, 1990). An interesting point about this theory is the final aim of this study, which like others is focused on economic growth as the ultimate goal. In his view, development and growth are similar. Many scholars believe that Lewis is the founder of economic development as a special and independent filed of economics. Nevertheless, it is truth he also repeats what last economists and social sciences have said about the goal of human life. He mentions that we should consider the word of development is feature of countries, which have been colony of advanced economies. Lewis claims the economic structures in each society have been divided to two parts: traditional part, which includes agriculture with low productivity and surplus of labors. In addition, industry that high rate of productivity is the most important feature of it. Industry is able to attract gradually the surplus of labors from agriculture(Lewis, 1955).

If we judge optimistically, we should say this theory entailed unintentionally agriculture was destroyed in developing countries like Asian, African and Latin American society, against he says we should concentrate on exporting the agricultural goods. In Seventies, most developing countries use the import substitution policy to provide the demand of agriculture production of their residents. However, some economic expert express that Lewis in his theory persuades the developing countries to export the agricultural raw materials, we can even claim pessimistically Lewis was completely aware to transfer the labor forces from agriculture to industry since it can cause these countries still dependent on advanced countries. It is clear that we cannot deny the development of industry has been result of development of agriculture. Economists confirm that England could have the first class loom industry in the world since it had access to Indian land of cotton. Overall, what point is important for us is that Lewis theory like others offer solutions for countries of third world to have high economic growth in his opinion also when human can be happy and lucky which have more money and wealth. Rostow is other economist who believes to develop our society we should move to industrial community. In his view what can provide the social welfare for the residents, is the economic growth that it will appear in our country by industrialization. He clarifies development process includes five stages which their goal is to reach economic growth as only instrument to create the public well-being (Rostow, 1955). Paying attention to economic growth, as a major tool to reach highest level of standard of living, is the key subject, which Rostow has pointed in his theory. Although we cannot disprove it, economic growth is not enough to develop societies. The interesting point, which that Rostow emphasizes on it, is the intervention of advanced countries especially the United States to help developing areas. He claims third world's residents are inherently schismatic also they are unaware of growing the science and technology, as 
result, appearance of developed communities because they learn modern science and new technology as well as they will know advanced culture also the political convulsions will decline in their regions. In other world, they will feel peace and democracy(Rostow, 1955).

It sounds, what Rostow has explained is only justification to intervene west countries. Though we do not like to have pessimistic judgment in this paper, we strongly believe attendance of western in developing countries not only help them to improve their situation but also is an explanation to despoil raw and scare resources. The experiments of developing countries showed when they could be successful to achieve economic growth; they rely on their power and try to change modern technology or social, economic and political plans according to their native indicators. Hirschman, by enforcing of combined development in Colombia in 1955, illustrates development consists the process of imbalance growth and allocating of money resources to functions which need investment. Hirschman in his theory "imbalance growth" displays at first, we should choose the strategic part of economy, which have the maximum profit for our society. Investing in these selected parts of economy caused these parts as a leader of growth process pull other parts of economy like a Locomotive. As result, the growth of advanced industries and areas will transfer to underdeveloped sections (Hirschman, 1972). Here we do not want to criticize the theory of "imbalance growth" only we mention that Hirschman is also showing the development process as economy is growth and everybody try to improve the level of production of different parts of economy. Schumpeter defines development is as optional changing in business cycle which are result of innovators who look for the profit (Schumpeter, 1961). This definition is enough that we understand his theory has formed base on economic growth. Schumpeter believes that innovation is the engine of economic growth since in a free economy we face depression which if it continues, economy will decompose because of depreciation of productions. Then innovators can only rescue the economy by their innovation in production process. Schumpeter explains that innovators are people who have the high knowledge, ability to do, accepting risk, and willingness to reach profit (Schumpeter, 1961).

Although in theory of Schumpeter, we need tools to bring up innovators like social background, technical knowledge, needed capital, low intervention of government, raw resources, new markets, financial supporter and so many factors that we cannot focus on it as development theory. As said before, the aim of this theory is also to achieve economic growth to satisfy what people require to have happy life. Another theory about economic growth is the theory of Clark. He illustrated the development degree of countries can be shown by transferring of labor force among different parts of economy. Clark explains that in developing countries we need minimum investment to create infrastructures like public transportation, which is necessary to grow the agriculture (Clark \& Haswell, 1964). The positive point about the economic growth theory of Clark is that, he believes development of industry and services need an advanced agriculture. In short, he accepts the truth which development in advanced countries has been a smooth process that it has started from agriculture. Of course, there are so many critics about the theory of Clark, and although it was one applicable theory for developing countries, what Clark has only pointed was growth of economic. Labor force, advanced agriculture, growth of industry and services sectors is instrument to attain the economic growth. In other word, Clark also defines development as economic growth and progress. Prebisch, who has grown by the neoclassical thinking, criticizes seriously neoclassicism to persuade developing countries to follow extrovert development process. Prebisch, in his theory in 1949, draws picture of system, which the developed countries located, in the center and developing areas are at the circumference (Prébisch, 1950). The strong point of Prebisch's opinion is that his new glance to development progress in 1988. He believes that progress of a country depends on economic and social factors. Prebisch explains that we cannot separate economic variables from their social aspects. Follower countries have not been able to better their situation since they have made mistake to follow the developed countries and do what has exactly been done in north countries (Prebisch, 1988).

Although Prebisch recommends solving the problems of low developed countries, we need transformation of systems in all aspects; his solution is the weak point of this theory. Because Prebisch suggests to attain the progress and development process in developing countries, they need a system which includes humanitarian socialism and economic liberalism (Prebisch, 1988). It is obvious, determining of political system, without considering the situation of each country, is a kind of limitation which is forced countries also it is an obstacle to be freedom of human. In approaching nineties, development theory was gradually being formed based on changing of social institutions. We almost say Todaro is one of the first development economists, which 
offered his theory according to third world situation. He accepts that the historical experiments are not true for all the societies, but also to move forward should be considered separately the situation of each country. Todaro defines the word of development as a continuous improvement of a society, which has happened because of changing fundamentally in infrastructures and institutions. In that time a community can claim that it has prepared three basically factors to develop the country: livelihood, confidence, and freedom (Todaro, 1989). Although Todaro has offered a different definition of development in comparison with other economists and paid attention to transformation of infrastructures and institution, he finally concentrates on production and increasing the national income. On the other word, he explains development as economic growth. Bettering the economic situation of Southeast countries, like Japan, South Korea, Singapore, Malaysia, and Hong Kong, was a motivation for East development economists who offer their opinion and view. Hayami demonstrates development is possibility of escaping of poverty in developing countries. He believes the increasing income, to decline the poverty, depends on growing the economic resources, progressing in technology, and modern institutions, which they are parts of culture. Then the high levels of income appertain to evolution of social and cultural parameters. As result, the most important factor, which the developing countries have to consider, is attaining effective economic system, which is exactly based on social and cultural traditions. Hayami defines this economic system as mixture of market, government, and society (Hayami \& Godo, 2005).

Helpman, to explain his theory, starts with a question: why some countries are rich and some are poor? Helpman believes this question has never answered since Adam Smith. In short, Helpman describes economists could not solve the mystery of growth yet. Obviously, he only focuses on income per capita as a measurement to show the living standard and compare it among different countries. Although Helpamn does not deny the issues like political freedom, health, education, environment, and social security which people care them to improve their situation, he depicts the standard of living include all the social and economic objects but it is so different to measure them as well as how to weight these factors in the mixed measurement. For this purpose, using income per capita is the best and clearest factor to identify and compare the situation of different countries (Helpman, 2004). Ranis by investigating the last six decades also the trend of economic growth and improvement the situation of human, focuses on growth of economy. He enumerates factors like concentrating on the relationship between decentralization and democratization, material resources, foreign capital and political effort, which help developing economy. Ranis by studying parts of the world such as Africa, South Asia, and Latin America refer to worthy issue which we should consider two-way connection between economic growth and human development. In his opinion, when we can expect happening long-run improvement in human life and which is paid attention to growth and progress of human development in the same time (Ranis, 2004). Kanbur, to define and clarify the development process, depicts that influence of ideology has been more important than experience of different countries in evolution of development. Then he divides the process of development to three times: 1955 to 1980, 1980 to 2000, and 2000 up to now. Kanbur in his study concludes development should be defined as ideology of mixed of capitalism, and communist. In the other hand, development is integrated process from state, market, and urban society (Kanbur, 2004). In this theory, we are also witness the economic growth as a goal of each ideology.

Finally, Yusuf \& Deaton (2009) in his book "development economic through the decades" tries to demonstrate societies look for economic growth to decline the poverty. In other word, he emphasizes final aim for each community is to eradicate the poverty. Yusuf, by using the experience of developing countries after Great depression, displays although we need evolution of agriculture, industry, infrastructures, climate change, and the role of government, and even the process of globalization, all these issues should be done to attain the economic growth as a tools to reduce the poverty and improve the income equality (Yusuf \& Deaton, 2009). Since time of birth of economics up today, all economists have been thinking how to enhance the level of public welfare and the satisfaction of people. After ending of the World War II and the efforts for the reconstruction of the world, and exiting the economic development as subcategories of economy, all the countries from north to south move to build and construct the incumbent infrastructures to raise national production and the level of standard of living. In this time, small group was at the forefront of movement (developed countries) and rest of countries as following groups pursued these changes. In spite of many efforts of following countries to decline their distance with pioneer economies, by modeling from leader countries, but most societies failed and not only they could not achieve better position but also, experienced 
worse situation in comparison with past. It is clear that development is not one-dimensional notion, which we can offer separately definition for each dimension. The concept of development has been taken from ideology of each society, which form based on thoughts of residents of that society, and to define each dimension must be considered all the aspects. As result, when we call "economic development" our purpose is changes and movement foreword in a community when can improve the economic situation that it can move with ameliorated conditions of social, political, and cultural features.

We can strongly say that the most principal problem in developing countries is the huge mass of population who experience the low level of standard of living, and another problem, which this kind of countries, face them is that poverty, in most time, is not been only explained with economic variables and factors. Consequently, most experts believe that development is a concept, which should be described by both factors: economic and non-economic indicators. Undoubtedly, we can strongly say that the theory of development of Sen, one of the most prominent theory of development, with considering all the divers status like social, economic, political and cultural parameters can fill the vacuum of ignoring the non-economic factors. The theory of "Development as Freedom" not only define the freedom as the final goal of development, but also knows it as the development 's fundamental instruments which can boost the public welfare of people, enhance the level of standard living and as result improve the satisfaction of residents of a society. Sen believes that, now, we live in a world which faces unprecedented affluence in comparing with last one or two centuries. In development theory of Sen, development is defined as the real freedom of humanity. In his theorization, not only development is not equal with growth of national income, raise of personal income, industrialization, progress of IT and modernization, but also it is in contrast to these characteristics.

Accordingly, in process of development, we can result that freedom is important for two reasons:

- Measuring of progress of development direction should be done by boosting of people's freedom.

- Attaining development is dependent on free responsibilities of people. In other word, stable freedom based on responsibility is the main engine to development.

Moreover, Sen illustrates freedom is the goal of development as well as it is proper instrument to development. He counts five type of freedom

- Political freedom

- Economic facilities

- Social opportunities

- Clarity of commitments

- Supportive security

He believes that these freedoms can improve the ability of people to alter their social, political, economic, and cultural situation and achieve the highest level of satisfaction (Sen, 2001). An interesting point in theory of Sen is that development process in each region is different from others. Since he believes that the numerous aspects of freedom in each country is according to the culture of this area and we cannot expect copying of development plans from advanced countries by developing countries have successful result for them. Szirmai is another economists who believes to define the word of development we should consider both economic and non-economic factors. He, by relying on Myint's theory (1980), displays that development can be identified in two views (Szirmai, 2005):

- Development is a conflict with poverty. According to this viewpoint, in developing countries, the original problems are the poverty, famine, starvation, and widespread disaster. Then the main concern of economists in these countries is how to improve the situation of residents in short time.

- The approach, which focuses on development as a long-term progress, and by studying on historical terms and different situation of countries, brings out the factors which impacts on social and economic evolution.

The central core of the first approach is based on widespread poverty in developing countries. Szirmai believes that in these countries, three routes are defined to achieve their goals. Route one, which has been called technocrats, concentrates on instruments and projects. In route two experts opt a radical-political way. Moreover, route three, people focus on a political practices to gain a demonstrative changes (Szirmai, 2005). Nevertheless, the focus of second view is on being long-term progress. One group seeks the answer of this question why there are many differences in development process among different countries in long time. But 
one group endeavor to recognize facts which can clarify numerous type of development like efficiency, technological movement, external political, economic impression, historical factors, and differences in culture for long period. Sen in the comprehensive and complete theory of development, explains that elimination of unfreedom means development, also he describes unfreedom consists economic and non-economic obstacles which can restrict the directions and situation of achieving the high level of standard living and satisfaction. Szirmai in his theory point's development is concept includes economic and non-economic factors, which will happen in long term. Thereupon, we can strongly say economic development is not separated from other dimensions of development, when we can experience attaining economic development which occurrence a comprehensive progress in society by all the economic and non-economic factors. It will entail that the upgrade of public welfare. Therefore, we should say that economic development arise in a society which all the dimensions like social, economic, cultural, and political will move forward and improve their position. Then this situation is equal with development process. As result we can claim when economic development happen that social development also occurrence according to this issue, Morris and Farrai offer their theory, which is describing the complete real concept of development process in each society. Morris asks this question why western countries could always move forward in comparison with other societies (Morris \& Farrar, 2010). It seems western could always determine all the law and plans for most countries which almost are poor. Domination of Europe on maritime trade, in half of eighteenth century, colonization, and transformation of western culture to eastern countries like changing the native language to English and national orthography of are examples which shows western has always desired to be leader of the world.

To answer this question we face two groups of opinions:

First group which has been named lock-in, being long-run is the most significant characters of this group, is based on ability of western country to overcome whole the world because of strong culture, appropriate climate, and religious beliefs. Second group are the short time models which is called random theory pointes this issue that key to success of western, to dominate poor countries, is to attain the their recourses of fossil fuels, it could transfer the power to advanced communities. Of course, Morris believes we can answer this question easily because has been offered diverse discussion, which has had several result in different times. He explains may be the best answer to this question is the social development, which means the ability of a group of people in a society to achieve the highest rating of physical and intellectual environment. In better world, social development is a collection of cultural, organizational, and technical abilities, which help residents of a society to have food, cloths, and housing, opportunity of fertility, as well as to defend them versus attacking other societies, finally to solve their problems and to develop the different discussion and issue in their communities. In other word, social development means ability to find and know the people's power and their position with the highest ranking of prestige among other countries. In conclusion, Morris mentions four major factors as independent variables to make the social development that they are: Energy Capture, Organization, War-Making Capacity, and information Technology (Morris \& Farrar, 2010). However, what we look for it, is this issue, development is result of economic and non-economic factors which economic growth is one of the tools to achieve the highest level of satisfaction of people who lives in society. In other hand, we should say the economic development is not a very facile concept to understand and investigate. Various subjects organize the basic of this notion, which is obtained according the conceptual discussion, and new insight that is result of experimental doing and study on behavior of people and societies. This new view illustrates that societies seek development not economic, social, political, and cultural development. Development is a collection of difference notions such as economy, society, politics, and culture which they have strong relationship with each other. We can expect one aspect of this collection happen without occurring others. Consequently, what communities should look for it is the whole the set of development that is has offered a new definition in next part.

\section{Results}

The perfect economic situation of Western Europe and North America countries due to the high national production in comparison with other countries, which has been named developing and under developing, caused these countries are noticed as a reference or symbol or sample for developing areas. Nevertheless, the experience of developing countries confirmed the most them not only do not ameliorate their economic situation but also, in some countries the poverty was vastly spread and people had the worse situation in a comparative discussion. Consequently, this event illustrates development is not similar growth and it needs 
factors which most of them are not economical. Moreover, we think the economic development is a notion, which reflects the whole of the social subjects and directly relates with behavior of humanity and what satisfy the human spirit. When people are unsatisfied, we cannot exactly expect to be in well-being circumstances. For example, in France as a developed country, attendance of Muslim women with veiled in governmental university, organization, and institution is forbidden. We mean, the women freedom is limited in this country and Muslim women always are discontent then it is possible that the dissatisfaction declines the motivation and tendency to be active in economic progress. Consequently, productivity, national production, national income, and level of welfare will be reduced in long run. Economic as a kind of social science has been constructed on two pillars: humankind and social system, which its goal is to create satisfaction as well as improve the level of standard of living albeit, Todaro and Smith believe the economic investigation and analysis cannot explain the behavior of human when society face vast hungry, poverty, illness, (Todaro \& Smith, 2011).

Our world has been divided two parts: first side has been named developed or first world by the high rate of national production and employment, low rate of poverty and justified distributed income, low rate of mortality and so many variables that show residents of this part are happy and satisfied. In contrast, second side is called developing or third world is not similar north and the considerable point is that from 7 billion population of the world about 6.4 billion people live in south. Features like the low level of GDP, high level of fatality especial in women and babies, high rate of children who have to work, and low rate of literacy show adversity of human in this part of the world. In a traditional view, economic development is capacity of increasing of national economy whose generate an annual raise in gross domestic production (GDP). Of course, we cannot ignore the increased production or growth of GDP cause to promote human life and reduce problems like poverty, hunger, depression in people, violence, and delinquency but it can make problems like what, nowadays, the people of the world are scrimmaging. For example, the spread of greenhouse gases or the problems of nuclear waste disposal are what, today, the development countries face them. To understand better the difference between economic development and economic growth, consider the table 1, which is related to gross domestic production per capita and life expectancy, where they are index of economic development, for five countries: China, Seri-Lanka, Brazil, Mexico, and South Africa by 2010. As shown by the table 1, the GDP per capita in South Africa is higher than China and Seri-Lanka but the life expectancy in this country is noticeably lower than they are. Moreover, this result is true when we compare between Brazil and Seri-Lanka. In addition, we can show this comparison between GDP per capita and Happiness. Table 1 illustrates this relationship:

Table 1: GDP and Life expectancy

\begin{tabular}{lll}
\hline & Life expectancy in born & GDP per capita \\
& $\mathbf{2 0 1 0}$ (year) & $\mathbf{2 0 1 0}$ (\$Constant 2000) \\
\hline China & 73.3 & 2426.3 \\
Seri-Lanka & 74.7 & 1308.7 \\
Brazil & 73.1 & 4716.6 \\
Mexico & 76.7 & 6124.7 \\
South Africa & 52.1 & 3753.4 \\
\hline
\end{tabular}

Source: World Bank Data (2012)

Table 2 shows that the relationship between GDP per capita and Ranking of Happiness among four countries, China, Brazil, South Africa, and Turkey. As been shown, the GDP per capita in 2010 for turkey was about 7833.5 and in Brazil this amount has been 5618.3 while Brazil is the twenty forth country of the World with the index of happiness about 6.849 but in turkey this amount is 5.345 and it is the seventy seventh countries of the world. Moreover, we can compare between China and South Africa which although the standard of living in Africa is higher than China, residents of China are Happier than South Africa. This comparison shows that we must not introduce the economic development instead economic growth they are not the similar. Although, increase of GDP by being constant other situation should improve the life of people and usually can raise the longevity, so many variables are which influence the life situation and the notion of development cannot ignore them. Deficiency of GDP as a measurement of being in welfare situation, also the new look 
glance of development in theory of Sen, based on income and wealth are only instruments to measure the well-being indexes and they are not our goals, disclosed that we need more complete tools of deliberation to investigate the different dimension of development. To understand better, Sen explains the poverty cannot only be shown by relative income since it is not important what we have or even what we feel but also, when we can claim that have eradicated the poverty, people can be or do what they want (Sen, 2001).

Table 2: GDP and Ranking of Happiness

\begin{tabular}{llll}
\hline & $\begin{array}{l}\text { Ranking in the world } \\
\mathbf{2 0 1 0}\end{array}$ & $\begin{array}{l}\text { The Index of Happiness } \\
\mathbf{2 0 1 0}\end{array}$ & $\begin{array}{l}\text { GDP per capita 2010 } \\
\text { (\$ Constant 2005) }\end{array}$ \\
\hline Brazil & 24 & 6.849 & 5618.3246 \\
Turkey & 77 & 5.345 & 7833.52866 \\
China & 93 & 4.978 & 2869.09382 \\
South Africa & 96 & 4.963 & 5794.33635 \\
\hline
\end{tabular}

Source: (Helliwell, Layard, \& Sachs, 2012)

It is evident; the purpose of development study is to attain a better and high level of standard of living. Development with all its subsets and derivatives including social, economic, political, and cultural will cause we have better understanding of our environment and societies which we are living and how to solve our different problems and difficulties which are sometimes barrier to achieve the our final goal, means having a happy life by so high level of satisfaction. While, too many theories about development have been offered which most them emphasize on economic motivation of development. When we talk about development, people pay attention to economic growth, increase of usage of new technology, level of industrialization, and like that. It seems the theory of Sen about development is the most complete opinions that have been offered up to now. As pointed before, Sen in his theory credits development is freedom. (Sen, 2001) In his view, freedom not only is the final goal of development but also is the powerful instrument to development. He explains that focus on freedom as development when is considerable that we recognize the relationship among different dimensions of freedom. For example, the political freedom helps us advancing of economic securities. Social opportunities simplify the economic participations. Economic facilities also increase the income of people and provide the required resources to create the social facilities.

With all due respect, to Professor Amartya Sen and mentioning the topic that, we should firmly follow the subject that economy and development, based on freedom, are informed and responsible concepts, which if the enough social opportunities are prepared, people can build their future. Therefore, we should not expect which human only receive the achievement of development programs but also they must have dynamic and positive role to construct their destiny. As result, here, we can define the development as providing needed background to flourish the talent of free human to build their future to achieve the high level of satisfaction. Overall, it is better to say that development is an intellectual and ideal concept, which no societies has completely experienced yet and what countries follow it, by different plans and policies, is advanced implication of economic growth. Then we believe the economic development is the set of the economic growth and social development, as the integration of changes in culture, politics, and societies, to provide the necessary background to flourish human talent and potential. In other word, to achieve development, we need groundwork to show and use our capabilities and capacity to produce the more goods and services and to raise the social, cultural, and political indexes and create the welfare and well-being for humankind. Finally, the important and interesting point, should be considered, is the differences in essential background to appearance, and bring up the human capacity in different societies. It means the notion of human will be defined according to the especial ideology in each society. Therefore, countries can prepare the incumbent groundwork to appearance the people basis on the beliefs, values, and dos and don'ts that belong to each community. Moreover, different ideology has caused not only, copying of development models from developed areas cannot solve the problems of developing and under developing countries but also, in most time their situation has been worsened. Now by this discretion of the economic development, it is better to be replaced by only development as a collection of positive economic, social, political, and cultural changes. 


\section{Conclusion}

Economic development is a current phrase with acceptable goals but the obscure concept. Genesis of this word refers to years after World War II when the countries started to reconstruct infrastructures, which had been destroyed in the war. In addition, many countries in these years became independent. Although, before the Second World War most economists believed that economy should also answer this question how can an economy grow and improve its situation besides replaying to these question, what things, how much, how and for who must be produced. For example, Smith (1776) repeatedly refers to economic growth topics by competitive market mechanism. However, there is a truth which, development can be defined by a dipole view. First the opinion, which assesses the concept of development with, measures like growth of national production, increase of income, industrialization, growth of IT and technology. Second the sight that evaluates the development as progress of real freedom and only has one measure, which is the satisfaction of people of a society. As we know, most economists, from smith up to now, have emphasized on the first viewpoint. Nevertheless, by selecting the first view is forgotten the most important components of development, which are fundamental for development process, and the absence of them can destroy the aims of economic development, also deprive the development of having required instrument to achieve its goals. While the second option of development definition has been examined in the whole of the world and has proved its performance. In addition, first definition of development looks for income, it means, the goal of development is attainment of high level of national income for each society. However, our second choices of defining the development seeks the situation which people feel peace and are satisfied form their life. They are happy and live without any limitation but freedom dose not bother others. Although, the national income, itself, is an achievement can promote our satisfaction and help us to attain the happiness and calmness as an appropriate tool.

In short, difference between two views of definition of development refers to emphasis on income and wealth from the first option and focus on being free and freedom. Since we strongly believe a society will develop when ability and capacity of societies will be improved and increase to prosper the talent of human. As result, we can claim when it happen that the freedom is born. Overall, we should have new regard to development and it seems to be necessary to offer the more complete definition of notion of development, which involves all the economic and noneconomic parameters to flourish the talent of human to be at peak of standard of living. With all due respect, to Professor Amartya Sen and mentioning the subject that, the theory of development as freedom is the most complete theories about development, we should firmly follow the subject that economy and development, based on freedom, are informed and responsible concepts, which if the enough social opportunities are prepared, people can build their future. Therefore, we should not expect which human only receive the achievement of development programs but also they must have dynamic and positive role to construct their destiny. As result, here, we can define the development as providing needed background to flourish the talent of free human to build their future to achieve the high level of satisfaction.

\section{References}

Clark, C. (1940). The conditions of economic progress (Vol. 195): Macmillan London.

Clark, C. \& Haswell, M. R. (1964). The economics of subsistence agriculture. The economics of subsistence agriculture.

Grabowski, R., Self, S. \& Shields, M. P. (2007). Economic development: a regional, institutional, and historical approach: ME Sharpe Inc.

Hayami, Y. \& Godo, Y. (2005). Development economics: from the poverty to the wealth of nations: Oxford University Press.

Helliwell, J., Layard, R. \& Sachs, J. (2012). World happiness report.

Helpman, E. (2004). The mystery of economic growth: Harvard University Press.

Hirschman, A. O. (1972). The Strategie of Economic Development.

Kanbur, R. (2004). The development of development thinking. Journal of Social and Economic Development, $6(2), 147$.

Keynes, J. M. (2006). The general theory of employment, interest and money: Atlantic Publishers \& Distributors.

Kindleberger, C. P. (2009). Marshall plan days: Taylor \& Francis. 
Lewis, W. A. (1955). The theory of economic growth: Allen \& Unwin London.

Malthus, T. R. (1926). First essay on population 1798.

Marx, K. \& Engels, F. (1967). The communist manifesto (1848). Trans. AJP Taylor. London: Penguin.

Morris, I. \& Farrar, S. (2010). Why the West Rules-for Now: The Patterns of History and what They Reveal about the Future: Profile Books.

Myrdal, G. (1990). The political element in the development of economic theory: Transaction Publishers.

Nielsen, L. (2011). Classifications of Countries Based on Their Level of Development: How it is done and how it could be done: International Monetary Fund.

Prebisch, R. (1988). Dependence, development, and interdependence. The State of Development Economics. Oxford, United Kingdom: Basil Blackwell.

Prébisch, R. (1950). Economic Survey of Latin America 1949. New York: United.

Ranis, G. (2004). The evolution of development thinking: theory and policy. ABCDE, 119.

Ricardo, D. \& Hartwell, R. M. (1971). On the principles of political economy, and taxation (Vol. 165): Penguin Books Harmondsworth.

Rosenstein-Rodan, P. N. (1957). Notes on the Theory of the big Push: Center for International Studies, Massachusetts Institute of Technology.

Rostow, W. W. (1955). Some general reflections on capital formation and economic growth Capital Formation and Economic Growth (pp. 633-666): Princeton University Press.

Schumpeter, J. A. (1961). The theory of economic development: An inquiry into profits, capital, credit, interest, and the business cycle (Vol. 55): Transaction Books.

Sen, A. (2001). Development as freedom: Oxford Paperbacks.

Singer, H. W. (1952). The Mechanics of Economic Development: A Quantitative Model Approach.

Smith, A. (1776). An inquiry into the nature and causes ofthe wealth ofnations. London: George Routledge and Sons.

Smith, A. (2006). An Inquiry into the Nature and Causes of the Wealth of Nations: Echo Library.

Szirmai, A. (2005). The dynamics of socio-economic development: an introduction: Cambridge University Press.

Todaro, M. (1989). Economic Development in the Third World: Longman, New York.

Todaro, M. P. \& Smith, S. C. (2011). Economic development: Pearson Higher Ed.

Weber, M., Baehr, P. R. \& Wells, G. C. (2002). The protestant ethic and the spirit of capitalism: And other writings: Penguin.

Yusuf, S. \& Deaton, A. (2009). Development economics through the decades: a critical look at 30 years of the World Development Report: World Bank Publications. 